\title{
Boundary Conduction Mode Controlled Power Factor Corrector With Line Voltage Recovery and Total Harmonic Distortion Improvement Techniques
}

\author{
Yi-Ping Su, Student Member, IEEE, Chia-Lung Ni, Chun-Yen Chen, Yi-Ting Chen, \\ Jen-Chieh Tsai, and Ke-Horng Chen, Senior Member, IEEE
}

\begin{abstract}
The proposed line voltage recovery (LVR) and the total harmonic distortion improvement (THDI) technique improve power factor (PF) and total harmonic distortion (THD) over a wide line voltage range in boundary conduction mode controlled power factor corrector (PFC). The LVR detects the input line root-mean-square voltage to generate the digital equivalent code to the THDI for optimizing the THD by tuning the on-time value at different line voltages. In addition, the LVR and the THDI provide a feedforward path to reduce the ripple of the feedback voltage for further improving the THD. Therefore, the PFC controller can keep high PF and low THD over a wide line voltage. Experimental results demonstrate that the peak $\mathrm{PF}$ value is 0.998 and the minimum THD is $1.7 \%$ by the test circuit fabricated in a TSMC 800-V ultrahigh-voltage process with the universal line voltage range of $90-264 \mathrm{~V}$.
\end{abstract}

Index Terms - Line voltage recovery (LVR), power factor (PF), total harmonic distortion (THD).

\section{INTRODUCTION}

G REEN POWER becomes more important in the world due to the lack of energy. In green power designs, highquality ac power conversion aims to enhance power utilization efficiency of the ac power supply, minimize power loss, and improve regulation. For increasing the power utilization efficiency of the ac power supply, the demanded power factor correction (PFC) converter can shape the input current of offline power supplies to be in phase with the line voltage. In addition, the total harmonic distortion (THD) of the line current, which also determines the quality of power source, is expressed in Fig. 1 and the following equation:

$$
\mathrm{THD}=\left(\frac{\cos ^{2} \theta}{\mathrm{PF}^{2}}-1\right)^{1 / 2}
$$

where power factor $\mathrm{PF}$ is the ratio of the real power to the apparent power, and $\theta$ is the phase angle between the line current and voltage.

Manuscript received December 12, 2012; revised March 25, 2013, May 25, 2013, and July 13, 2013; accepted August 13, 2013. Date of publication September 10, 2013; date of current version January 31, 2014.

Y.-P. Su, C.-L. Ni, C.-Y. Chen, Y.-T. Chen, and J.-C. Tsai are with the Mixed-Signal and Power Management IC Laboratory, Institute of Electrical Engineering, National Chiao Tung University, Hsinchu 300, Taiwan.

K.-H. Chen is with the Department of Electrical Engineering, National Chiao Tung University, Hsinchu 300, Taiwan (e-mail: khchen@ cn.nctu.edu.tw).

Color versions of one or more of the figures in this paper are available online at http://ieeexplore.ieee.org.

Digital Object Identifier 10.1109/TIE.2013.2281302

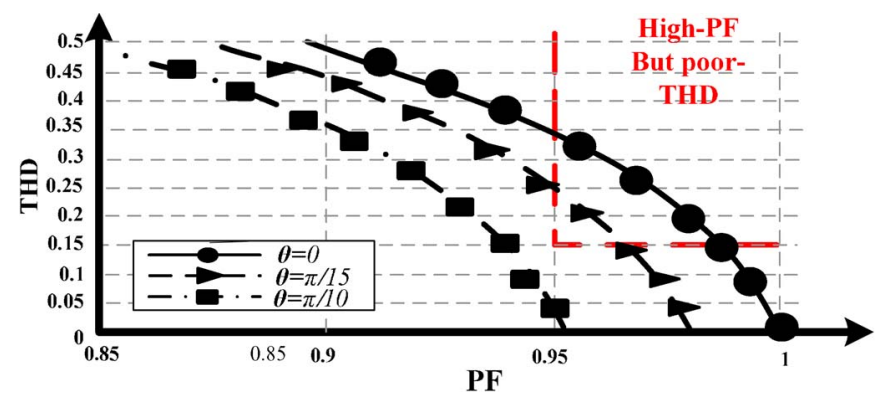

Fig. 1. Diagram of THD versus PF.

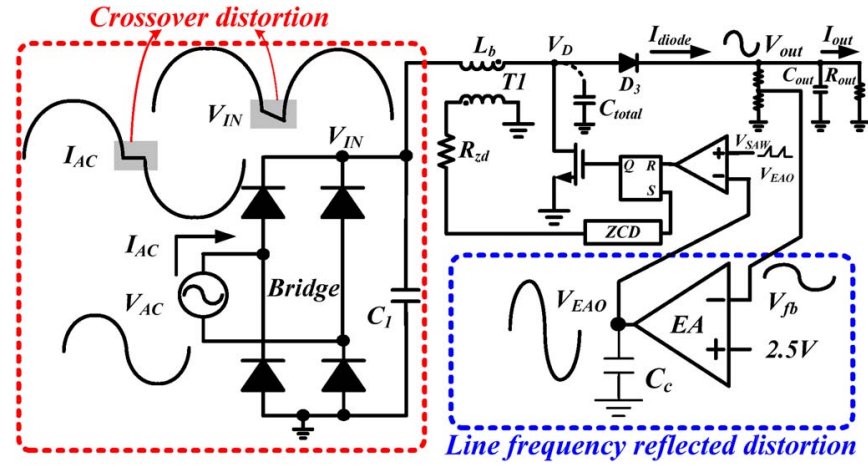

Fig. 2. Two major THD-deteriorated contributors in the conventional PFC with BCM control.

Interestingly, the relationship between PF and THD reveals that THD is still poor even if PF is high. That is to say, for high-quality power supply, both the PF and the THD are important. The harmonic currents will increase power losses on the transmission line and cause electrical equipment damages. Therefore, the THD needs to be decreased for high-quality power supply even if the PF is high. There are safety standards that determine the maximum THD of electrical products in many countries, such as EN61000-3-2. In other words, improving THD becomes an essential requirement for electrical products.

Basically, two major THD-deteriorated contributors are shown in Fig. 2 in a conventional PFC boost converter with boundary conduction mode (BCM) control [1]-[3]. One is the crossover distortion caused by the forward voltage of the diodes in the bridge and parasitic capacitances $C_{\text {total }}$, which includes the parasitic capacitance of $D_{3}$ and power nMOSFET. The other is the line frequency reflected distortion. The frequency 


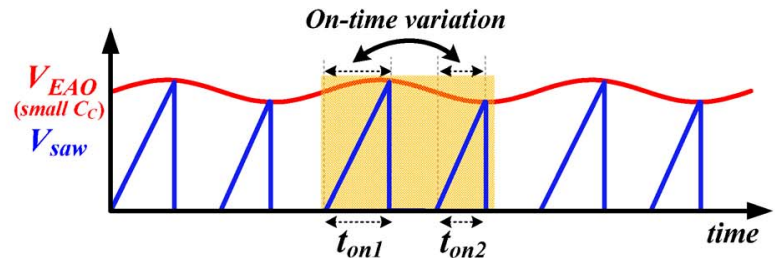

(a)

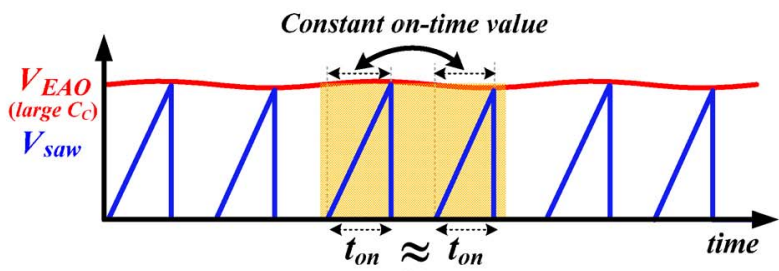

(b)

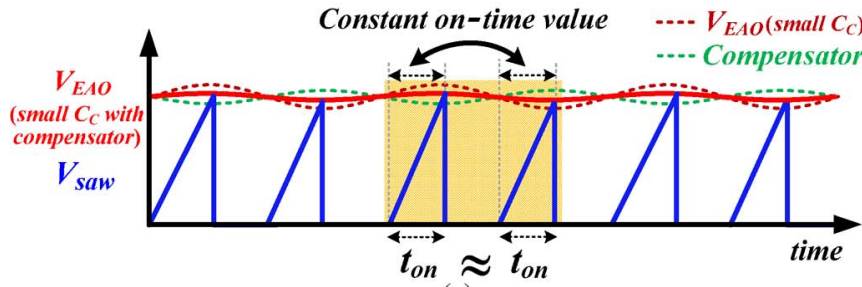

(c)

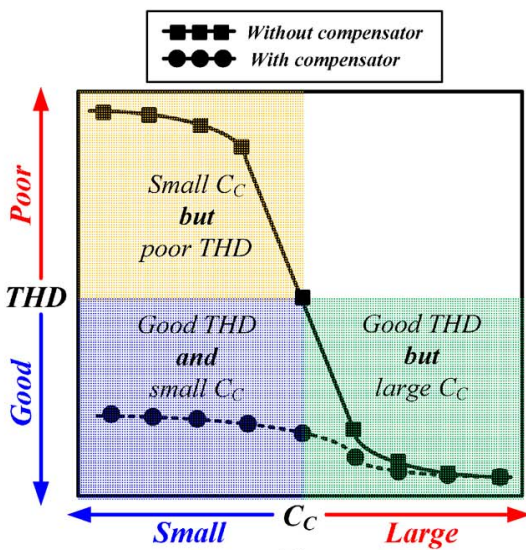

(d)

Fig. 3. (a) On-time variation is caused by the line frequency reflected distortion. (b) Variation of on-time value can be reduced by large $C_{C}$. (c) Variation of on-time value can be reduced by the compensator even with small $C_{C}$. (d) Relationship between $C_{C}$ and THD.

of the PFC output ripple is twice of the ac line. The reflected output ripple is fed into the feedback loop so that the output of the error amplifier contains the voltage ripple with twice the line frequency. The ripple brings the variation of on-time within an ac cycle, as depicted in Fig. 3(a). The on-time variation goes against constant on-time control, which is the general demand for the PFC boost converter with BCM control to lower the THD for satisfying standard requirements [4]. Hence, THD is deteriorated short of expected specifications due to line frequency reflected distortion. In general, a large compensated capacitor $C_{C}$ is used to keep the bandwidth within $20 \mathrm{~Hz}$ to reduce the gain of the error amplifier at twice the line frequency such that the PFC boost converter can operate with constant on-time control, as shown in Fig. 3(b) [5]. However, the solution occupies a large footprint area. In this paper, the ripple compensator is proposed to suppress the output ripple of the error amplifier. Therefore, constant on-time can be ensured even if a small $C_{C}$ is adopted, as illustrated in Fig. 3(c). The relationship between $C_{C}$ and THD is depicted in Fig. 3(d). In conventional PFC, the smaller the selected $C_{C}$ is, the poorer the THD performance will be. With the contribution of the ripple compensator, the small footprint area and the low THD can be simultaneously achieved.

On the other hand, a conventional BCM controller usually uses a shaping skill to minimize crossover distortion [6]. However, the multiplier, which multiplies the output of the error amplifier by feedforward input voltage for duty cycle generation, dissipates much power. Therefore, to alleviate both THD deteriorated issues, which contain crossover distortion and line frequency reflected distortion, line voltage recovery (LVR) circuit and total harmonic distortion improvement (THDI) techniques are proposed in this paper. THDI modulates on-time value based on the digital correction codes generated by LVR circuit to improve crossover distortion. Simultaneously, LVR and THDI form a feedforward path to reduce line frequency reflected distortion. Consequently, the two major THD-deteriorated contributors can be simultaneously and effectively alleviated to get high PF and low THD over a wide input line voltage range of 90-264 V.

This paper is organized as follows. The proposed architecture and the circuit implementation are illustrated in Sections II and III, respectively. Simulation and experimental results are shown in Section IV. Finally, a conclusion is made in Section V.

\section{Proposed ARChitecture With THE LVR AND THE THDI}

As shown in Fig. 4(a), the inductor $L_{b}$ can store enough energy during inductor charging phase normally. During inductor discharging phase, as shown in Fig. 4(b), total capacitance at node $V_{D}, C_{\text {total }}$, which includes the parasitic capacitance of $D_{3}$ and power nMOSFET, can be successfully charged up to the required voltage. The required voltage is the output voltage $V_{\text {out }}$ plus the turn-on voltage of diode $D_{3}$. Once diode $D_{3}$ is turned on, the energy stored in the inductor is delivered to the output, as shown in Fig. 4(c). Unfortunately, when the line voltage $V_{\mathrm{AC}}$ is near the zero-crossings, the inductor can still store the energy during inductor charging phase. Nevertheless, the stored energy is not enough to charge $C_{\text {total }}$ up to the required voltage during inductor discharging phase. As a result, diode $D_{3}$ will not be turned on. The energy is confined and dissipated in the tank circuit, which is composed of $C_{\text {total }}, C_{1}$, and $L_{b}$, and causes a resonance phenomenon, as shown in Fig. 4(d). The phenomenon is kept for an interval until the absolute value of the line voltage is larger than the voltage of $V_{\mathrm{IN}}$, which is the rectified line voltage.

During this interval, $V_{\mathrm{IN}}$ decreases at a slower rate determined by the losses of the power nMOSFET and the tank circuit. However, the line voltage decreases at a faster rate. Thus, the diode of the bridge rectifier cannot be turned on, and the flat portion in the line current $I_{\mathrm{AC}}$ happens, as illustrated in Fig. 5. This distortion is called "crossover distortion," which increases the number of the total harmonics in $I_{\mathrm{AC}}$ greatly. In other words, the THD becomes serious. 


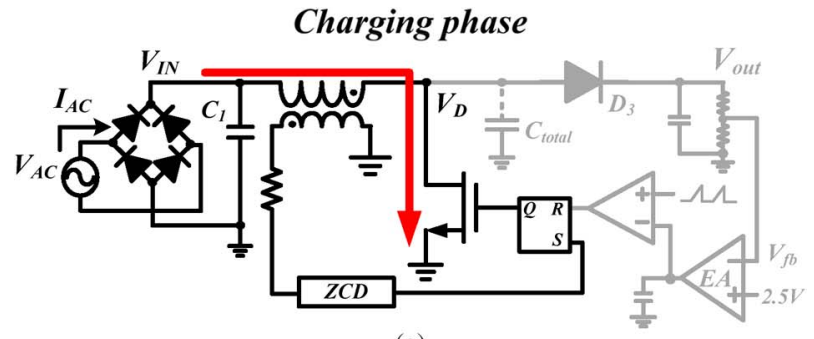

(a)

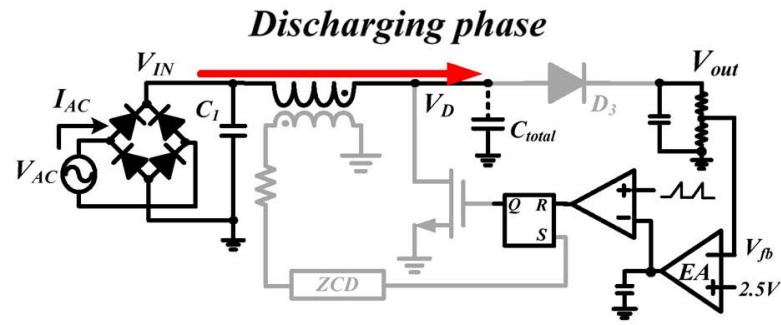

(b)

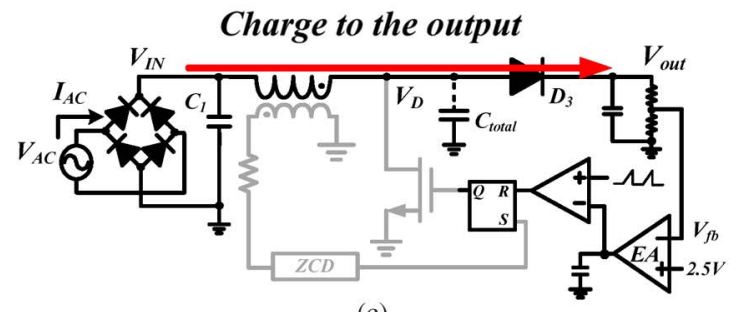

(c)

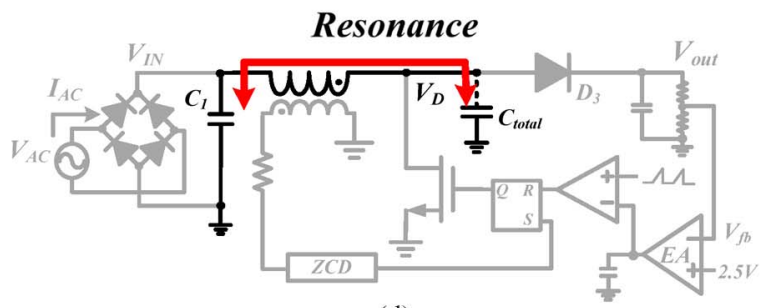

(d)

Fig. 4. (a) Charging phase of the PFC boost converter. (b) Discharging phase of the PFC boost converter. (c) Energy charges to the output when the line voltage is high enough. (d) Energy is confined in the resonant tank when the line voltage is near zero-crossings.

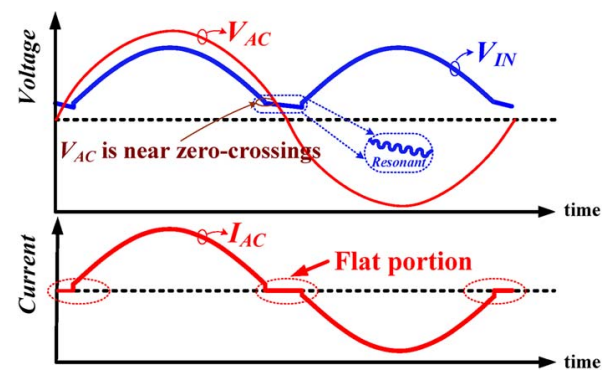

Fig. 5. Line voltage and current waveforms of crossover distortion phenomenon.

If the inequality shown in (2) is simply conformed, it means that the energy stored in the charging phase is not high enough to conduct diode $D_{3}$ in the discharging phase

$\frac{1}{2} L_{b} \cdot\left[\sqrt{2} I_{\mathrm{AC}, \mathrm{rms}} \sin \left(\pi-\phi_{d}\right)\right]^{2} \leq \frac{1}{2} C_{\text {total }} \cdot\left(V_{\text {out }}+V_{\text {diode }}\right)^{2}$

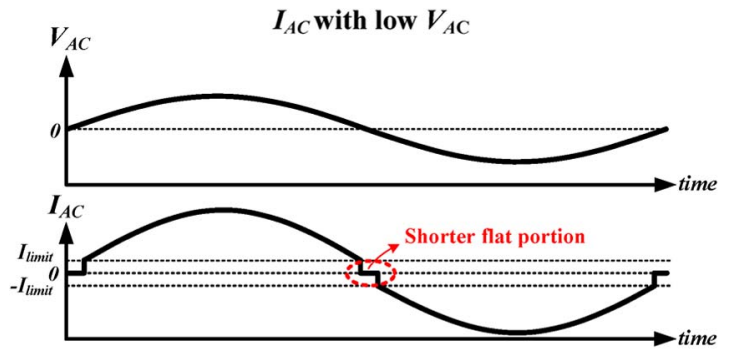

(a)

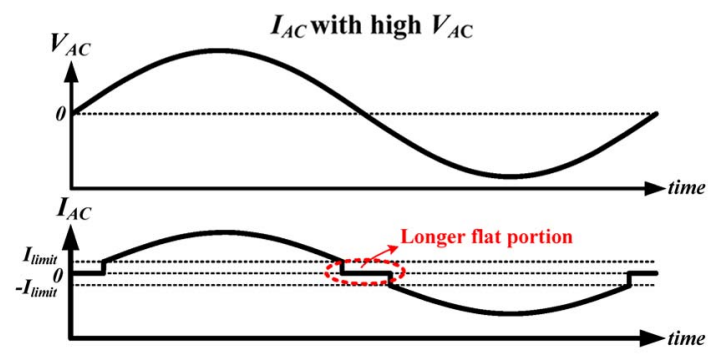

(b)

Fig. 6. Waveforms of the line current with (a) low line RMS voltage and (b) high line RMS voltage.

where $\phi_{d}$ is the crossover distortion angle, which indicates that $I_{\mathrm{AC}}$ starts away from the ideal sinusoidal wave; $V_{\text {diode }}$ is the forward voltage of $D_{3}$; and $I_{\mathrm{AC}, \mathrm{rms}}$ is the RMS value of the line current.

Here, $I_{\mathrm{AC}, \mathrm{rms}}$ can be expressed as (3) based on the relationship between power and current. $V_{\mathrm{AC}, \mathrm{rms}}$ and $P_{\mathrm{AC}, \mathrm{rms}}$ are the RMS values of the line voltage and input power, respectively, i.e.,

$$
I_{\mathrm{AC}, \mathrm{rms}}=\frac{P_{\mathrm{AC}, \mathrm{rms}}}{V_{\mathrm{AC}, \mathrm{rms}}} .
$$

The limiting current $I_{\text {limit }}$, which is defined as the required current that can charge $C_{\text {total }}$ up to the required voltage, is derived as (4). If the line current is lower than $I_{\text {limit }}$, the crossover distortion, which results in the flat portion in the line current, will happen, i.e.,

$$
I_{\text {limit }}=\sqrt{\frac{C_{\text {total }}}{L_{b}}} \cdot\left(V_{\text {out }}+V_{\text {diode }}\right) .
$$

Using the information of the line voltage to modulate the ontime value of the power nMOSFET can alleviate crossover distortion [7]. At a high level of the line voltage, the on-time value is slightly shortened. Contrarily, the on-time value is extended at the region of low line voltage near the zero-crossings. Therefore, the inductor current near the zero-crossings is increased to break through $I_{\text {limit }}$. The THD performance can be improved by compressing the flat portions.

However, good THD performance for universal input line voltage is unable to be achieved if the modulated on-time value is not adapted to the variation of the input line RMS voltage. With fixed output power, higher input line RMS voltage results in lower line current and larger flat portion, as depicted in Fig. 6(a). On the contrary, lower input line RMS voltage results in higher line current and smaller flat portion, as depicted in 


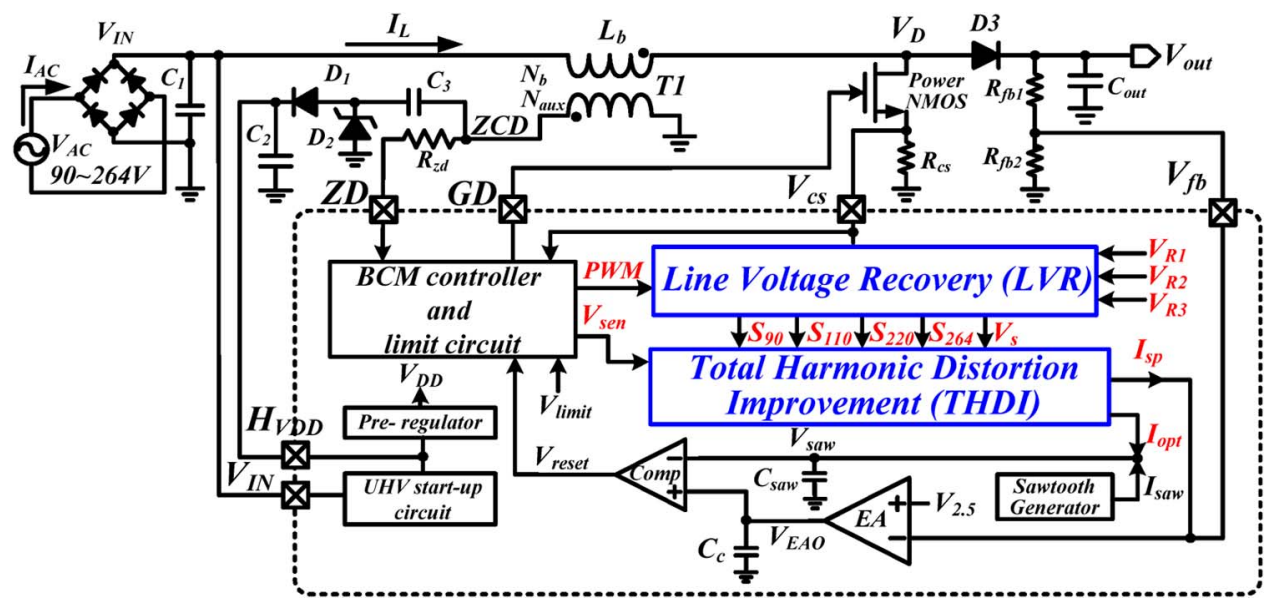

Fig. 7. Proposed BCM architecture with LVR and THDI.

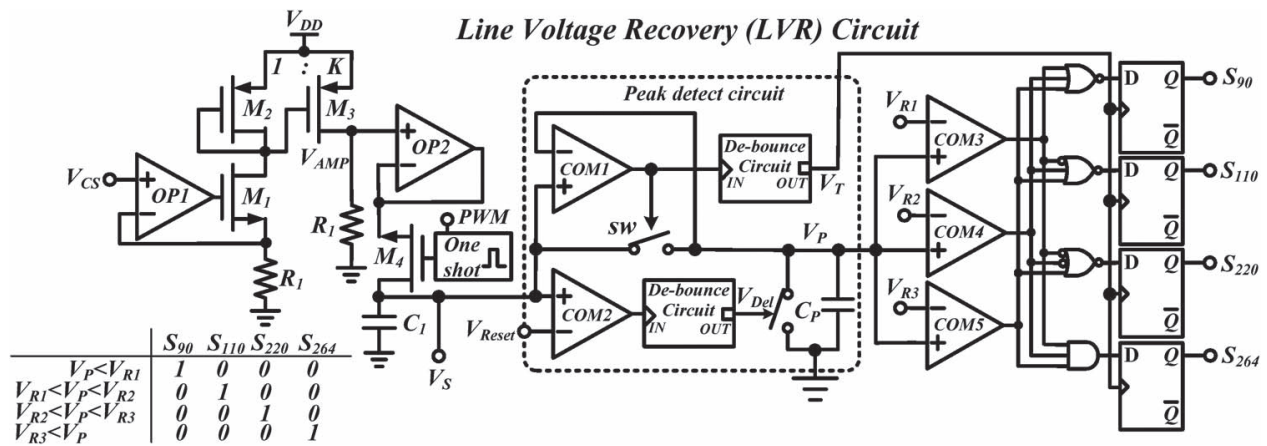

Fig. 8. Circuit implementation of the proposed LVR circuit.

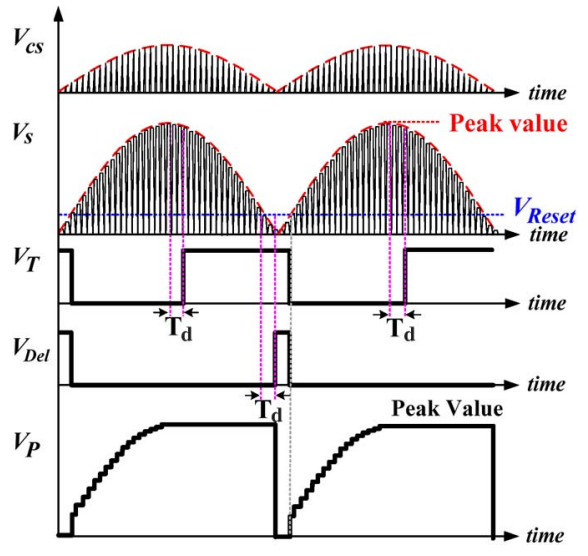

Fig. 9. Detailed operation waveform of the proposed LVR.

Fig. 6(b). The period of the flat portion, i.e., $T_{f}$, which results from the crossover distortion, is shown as

$$
T_{f}=\frac{\phi_{d}}{2 \pi \cdot f_{\text {line }}} \approx \frac{\sqrt{2}}{4} \cdot \frac{I_{\text {limit }} \cdot V_{\mathrm{AC}, \mathrm{rms}}}{f_{\text {line }} \cdot P_{\mathrm{AC}, \mathrm{rms}}}
$$

where

$$
\phi_{d} \approx \frac{\sqrt{2}}{2} \cdot I_{\text {limit }} \cdot \frac{V_{\mathrm{AC}, \mathrm{rms}}}{P_{\mathrm{AC}, \mathrm{rms}}}
$$

where $f_{\text {line }}$ is the line frequency. When the line RMS voltage is high, the crossover distortion becomes serious. Thus, the

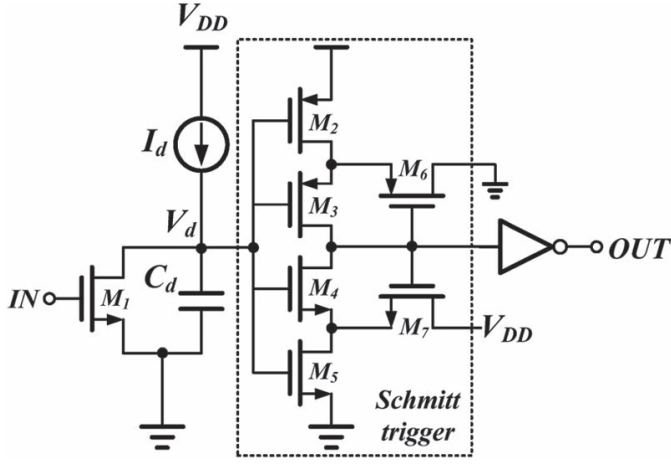

Fig. 10. Circuit implementation of the debounce circuit.

crossover distortion needs to be adaptively improved according to different line RMS voltages such that the THD can be maintained within a quite low level.

In addition, even if the modulated value of the on-time makes the flat portion becomes shorter gradually, the waveform of the line current is unlike the ideal sinusoid waveform and, thus, may distort the line current [8]. Thus, the level of the modulated on-time value has to be carefully designed at different line voltages to get good THD performance.

Fig. 7 shows the architecture of the proposed PFC boost converter, which is operating in BCM control in low-power applications. LVR can detect the input line RMS voltage to generate the digital correction codes, namely, $S_{90}, S_{110}, S_{220}$, and $S_{264}$, to THDI for optimizing the THD by tuning the 


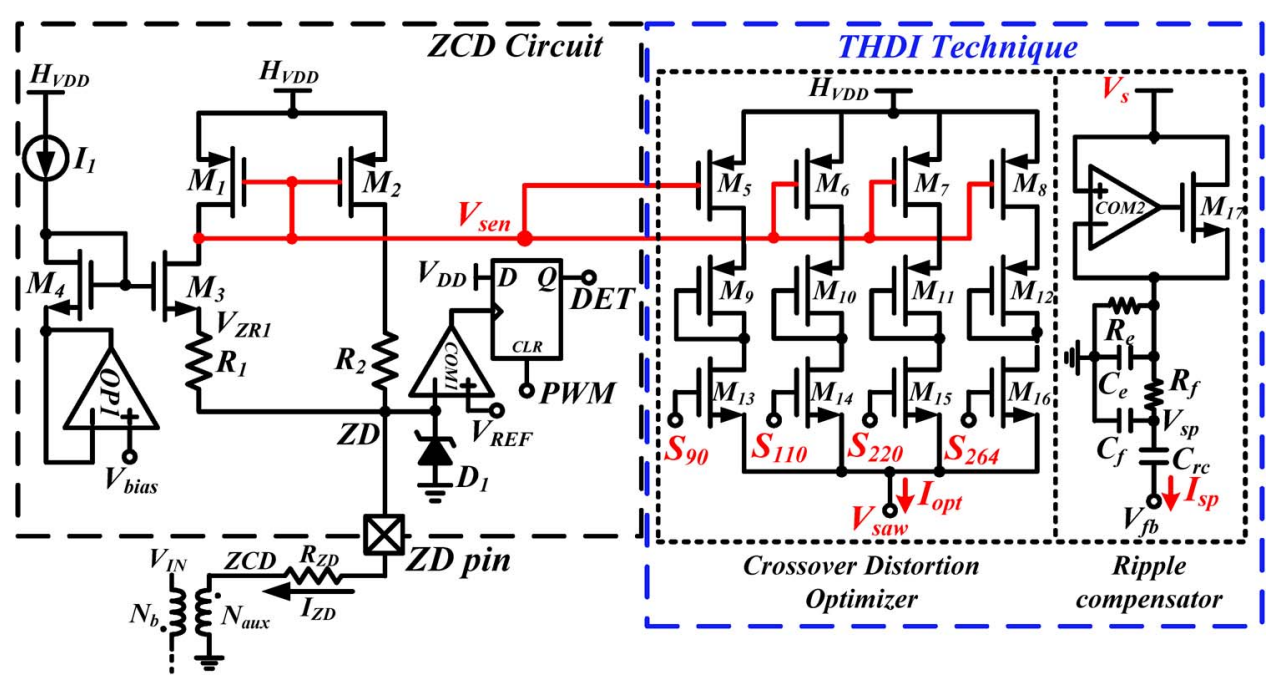

Fig. 11. Schematic of the ZCD and the THDI technique.

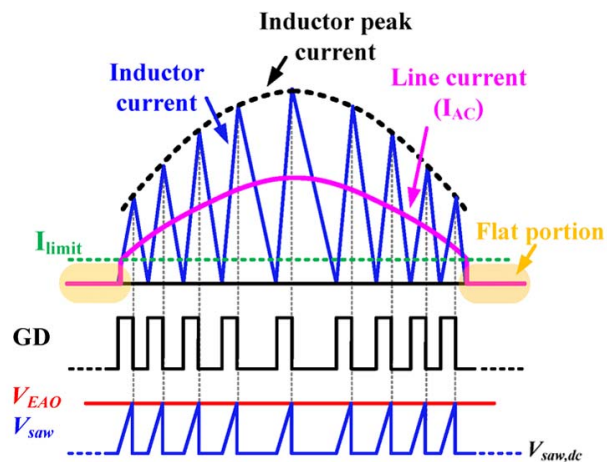

(a)

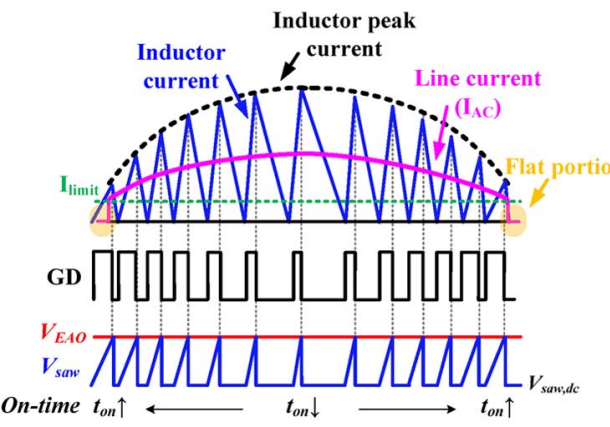

(b)

Fig. 12. (a) Control mechanism of a conventional PFC controller. (b) Control mechanism of the proposed PFC controller with the THDI technique.

on-time value at different line RMS voltages. In addition, LVR and THDI provide a feedforward path to reduce the ripple of the feedback voltage for decreasing THD. Therefore, high PF and low THD can be concurrently achieved over a wide range of the line voltage by the proposed method.

\section{Circuit Implementation}

\section{A. Proposed LVR Circuit}

According to different line voltages, the THD should be improved by different on-time values. In general, the peak value of the rectified line voltage $V_{\text {IN }}$ can indicate the RMS line voltage. In [9], one resistive divider is used to detect the

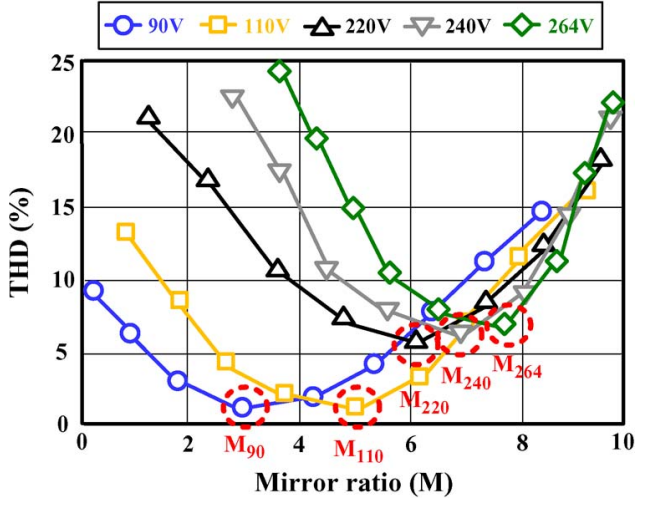

Fig. 13. Relationship between the THD and the mirror ratio at different line RMS voltages.

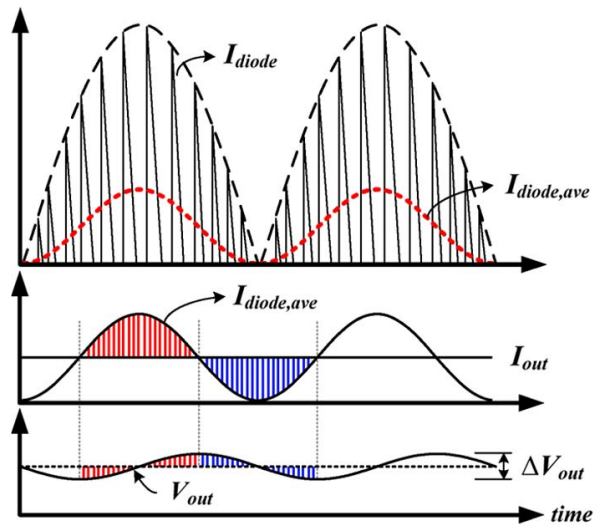

Fig. 14. Relationship between the diode current and the output voltage.

input line RMS voltage. Although the method can detect the input line RMS voltage successfully, it needs extra pins and discrete devices such that the efficiency is deteriorated and the cost increases. The proposed LVR circuit in Fig. 8 can use the inductor current sensing signal $V_{\mathrm{CS}}$, which is used for over inductor current protection originally, to reconstruct the sinusoidal-wave tendency of the line voltage and judge the input line RMS voltage. Since the LVR does not need extra pins and discrete resisters, the power consumption and cost can be reduced. 


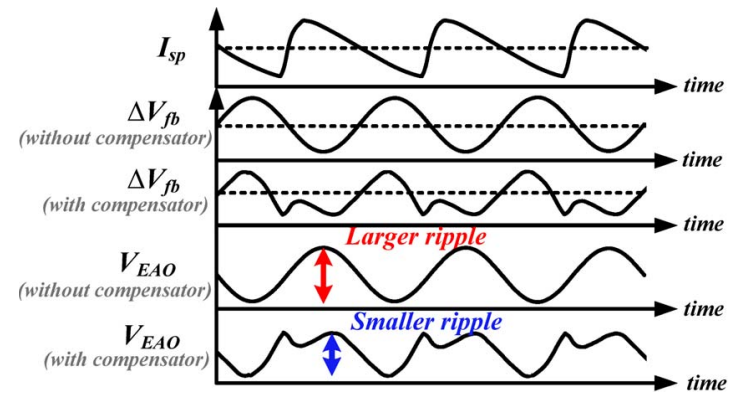

Fig. 15. Ripple of the feedback voltage and the output ripple of the error amplifier with and without the proposed ripple compensator.

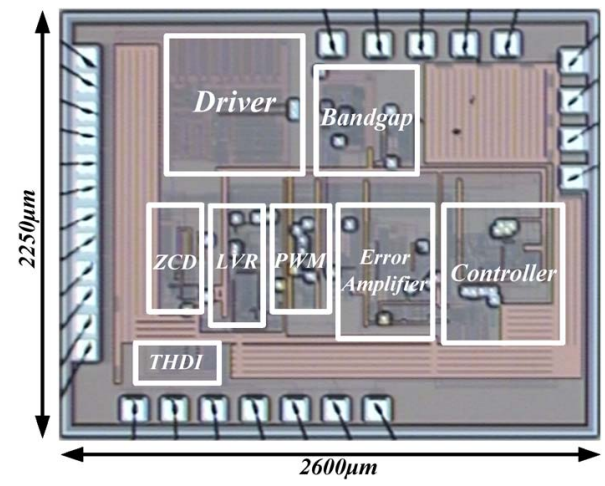

Fig. 16. Chip micrograph of the proposed PFC controller LVR and the THDI.

During the on-time period, the power nMOSFET is switched on, and then, the inductor current flows through the sensing resistor $R_{\mathrm{CS}}$ to obtain $V_{\mathrm{CS}}$. Without the on-time modulation of THDI, $V_{\mathrm{CS}}$ can be expressed as

$$
V_{\mathrm{CS}}=\frac{V_{\mathrm{IN}}}{L_{b}} \times R_{\mathrm{CS}} \times t_{\mathrm{on}, \mathrm{fix}}=\frac{2 \cdot V_{\mathrm{IN}} \cdot R_{\mathrm{CS}} \cdot P_{O}}{V_{\mathrm{rms}}^{2} \cdot \eta}
$$

where $V_{\mathrm{IN}}$ is the rectified line voltage, $L_{b}$ is the inductor value, $P_{O}$ is the output power, $V_{\mathrm{rms}}$ is the input line RMS voltage, $\eta$ is the conversion efficiency, and $t_{\mathrm{on}, \mathrm{fix}}$ is the on-time value of the power nMOSFET before modulation.

Since the on-time value varies with the input line RMS voltage $V_{\mathrm{rms}}$ and the output power $P_{O}$, the sinusoidal-wave tendency of the line voltage is unable to be obtained by $V_{\mathrm{CS}}$ directly. Furthermore, the range of $V_{\mathrm{CS}}$ is too large to use the differentiator [10] to reconstruct the line voltage. Instead of the on-time value, a fixed sampling time $t_{\text {sample }}$ is adopted to generate $V_{S}$ in the proposed LVR. Therefore, the dependence on the input line RMS voltage $V_{\text {rms }}$ and the output power $P_{O}$ can be removed. $V_{S}$ can reconstruct the sinusoidal-wave tendency of the line voltage successfully, as shown in

$$
V_{S}=K \times \frac{V_{\mathrm{IN}}}{L_{b}} \times R_{\mathrm{CS}} \times t_{\mathrm{sample}} \propto V_{\mathrm{IN}} \propto\left|V_{\mathrm{AC}}\right|
$$

where $K$ is the ratio of signal amplification.

In Fig. 8, the transistors $M_{2}$ and $M_{3}$ form a current mirror to amplify $V_{\mathrm{CS}}$ by $K$ times and generate $V_{\mathrm{AMP}} . V_{S}$ can be obtained by sampling $V_{\mathrm{AMP}}$ with a fixed sampling time $t_{\text {sample }}$, which is generated by triggering the one shot circuit with a pulsewidth modulation signal, through the sampling switch
TABLE I

DESIGN SPECIFICATIONS OF THE PROPOSED PFC WITH LVR AND THDI TECHNIQUES

\begin{tabular}{|l|c|}
\hline Technology & TSMC $0.5 \mu \mathrm{m} 800 \mathrm{~V} \mathrm{UHV}$ \\
\hline Input line voltage range $\left(V_{A C}\right)$ & $90 \sim 264 \mathrm{~V}(\mathrm{rms}$ value $) / 60 \mathrm{~Hz}$ \\
\hline Output voltage $\left(V_{\text {out }}\right)$ & $400 \mathrm{~V}$ \\
\hline Primary inductor $\left(L_{b}\right)$ & $460 \mu \mathrm{H}$ \\
\hline Primary winding turns $\left(N_{b}\right)$ & $60 \mathrm{~T}$ \\
\hline Auxiliary winding turns $\left(N_{\text {aux }}\right)$ & $8 \mathrm{~T}$ \\
\hline Output capacitor $\left(C_{\text {out }}\right)$ & $68 \mu \mathrm{F} / 450 \mathrm{~V}$ \\
\hline Output power $\left(P_{\text {out }}\right)$ & $90 \mathrm{~W}$ \\
\hline Switching frequency $\left(f_{s w}\right)$ & $35 \mathrm{kHz} \sim 250 \mathrm{kHz}$ \\
\hline Bandwidth $(\mathrm{BW})$ & $20 \mathrm{~Hz}$ \\
\hline Feedback resistors $\left(R_{f b} / R_{f b 2}\right)$ & $795 \mathrm{k} \Omega / 5 \mathrm{k} \Omega$ \\
\hline Sensing resistor $\left(R_{c s}\right)$ & $0.15 \Omega$ \\
\hline Total harmonic distortion $(\mathrm{THD})$ & $1.7 \%$ (Minimum) \\
\hline Power factor $(\mathrm{PF})$ & 0.998 (Maximum) \\
\hline Efficiency & $94.8 \%$ (Maximum) \\
\hline
\end{tabular}

$M_{4}$. Thus, the sinusoidal-wave tendency of the line voltage is correctly reconstructed. Moreover, the peak detector circuit detects the peak value of $V_{S}$ to judge the input line RMS voltage. The comparator COM1 decides the status of the switch sw. When sw turns on, $C_{P}$ samples the information of $V_{S}$. Once $V_{S}$ is smaller than $V_{P}$, sw turns off, and $V_{P}$ holds the value previously sampled. Consequently, $V_{P}$ keeps the peak value of $V_{S}$ within a half ac cycle until the reset signal $V_{\text {Del }}$ rises, as shown in Fig. 9.

$V_{T}$ indicates whether the peak value is detected or not. While $V_{S}$ is smaller than $V_{P}$ over the debounce time $T_{d}$, which is produced by the debounce circuit, $V_{T}$ signifies the calculation of the line RMS voltage. Comparing $V_{P}$ and the reference voltages $V_{R 1}-V_{R 3}$ sorted by increasing order, the level of the input line RMS voltage can be successfully detected. By synchronization of $V_{T}$, the 4-bit digital equivalent code, which is composed of $S_{90}, S_{110}, S_{220}$, and $S_{264}$, can be generated to indicate the input line RMS voltage. The truth table is shown at the bottom left in Fig. 8. For example, if the 4-bit digital equivalent code shows "0100," the input line RMS voltage is $110 \mathrm{~V}$.

Since $V_{S}$ returns to zero during every switching cycle, the debounce time $T_{d}$ has to be carefully designed to avoid generating incorrect signals. The debounce circuit, as depicted in Fig. 10, is used to avoid abnormal operation and noise interference. When the input signal changes from high to low, the current $I_{d}$ will charge the capacitor $C_{d}$. The debounce time is determined by $I_{d}$ and $C_{d}$. The hysteresis window is formed by the Schmitt trigger, the transistors $M_{2}-M_{7}$. If the node voltage $V_{d}$ can be higher than the upper bound of the hysteretic window and this condition can be longer than the debounce time, the output signal will be changed. Careful definition of the debounce time and the hysteresis window can ensure a robust system.

\section{B. Proposed THDI Technique}

The proposed THDI technique, as shown in Fig. 11, is composed of the crossover distortion optimizer and the ripple compensator. The proposed crossover distortion optimizer conquers 


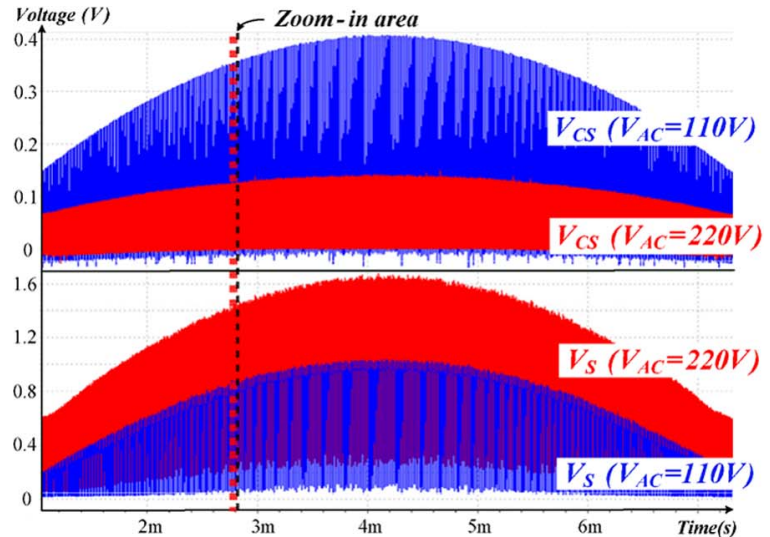

(a)

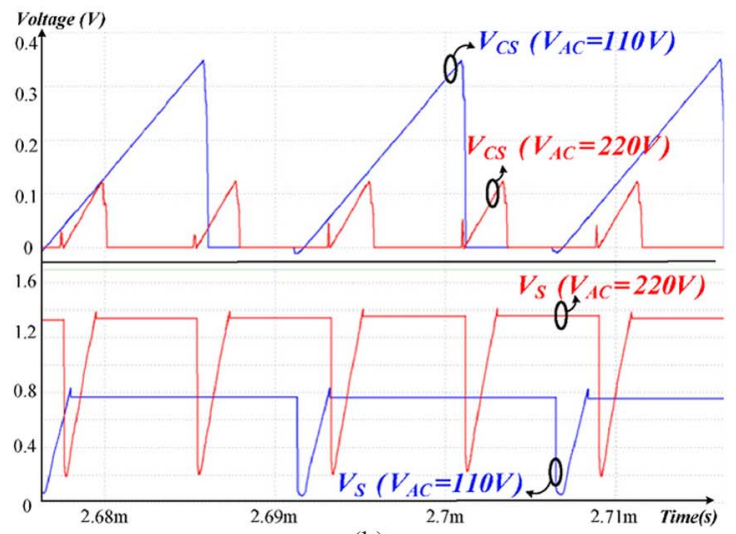

(b)

Fig. 17. (a) Simulation waveforms of the LVR circuit. (b) Zoom-in waveforms.

two major drawbacks for THD improvement in [2] and [3]. First, the requirement of extra resistors for on-time modulation deteriorates the efficiency of the PFC boost converter. Second, the THD performance cannot be ensured with different line RMS voltages.

The proposed crossover distortion optimizer alleviates the crossover distortion at different line RMS voltages without extra pin and discrete devices. Instead, the zero-current detection (ZCD) circuit, which is essential for the BCM control, is utilized. When the power nMOSFET is turned on, the voltage of $\mathrm{ZCD}$ node $V_{\mathrm{ZCD}}$ is shown as

$$
V_{\mathrm{ZCD}}=-\frac{V_{\mathrm{IN}} \cdot N_{\mathrm{aux}}}{N_{b}}
$$

where $N_{b}$ and $N_{\text {aux }}$ are the primary and auxiliary winding turns, respectively.

The transistors $M_{1}-M_{3}$ and the resistors $R_{1}$ and $R_{2}$ of the ZCD circuit form a negative feedback to clamp the voltage of

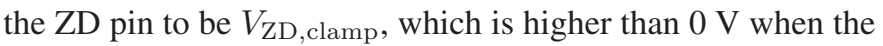
power nMOSFET is turned on. Therefore, the current $I_{\mathrm{ZD}}$ can be expressed as

$$
I_{\mathrm{ZD}}=\frac{V_{\mathrm{ZD}, \text { clamp }}-V_{\mathrm{ZD}}}{R_{\mathrm{ZD}}}=\frac{V_{\mathrm{ZD}, \text { clamp }}+\frac{V_{\mathrm{IN}} \cdot N_{\mathrm{aux}}}{N_{b}}}{R_{\mathrm{ZD}}} .
$$

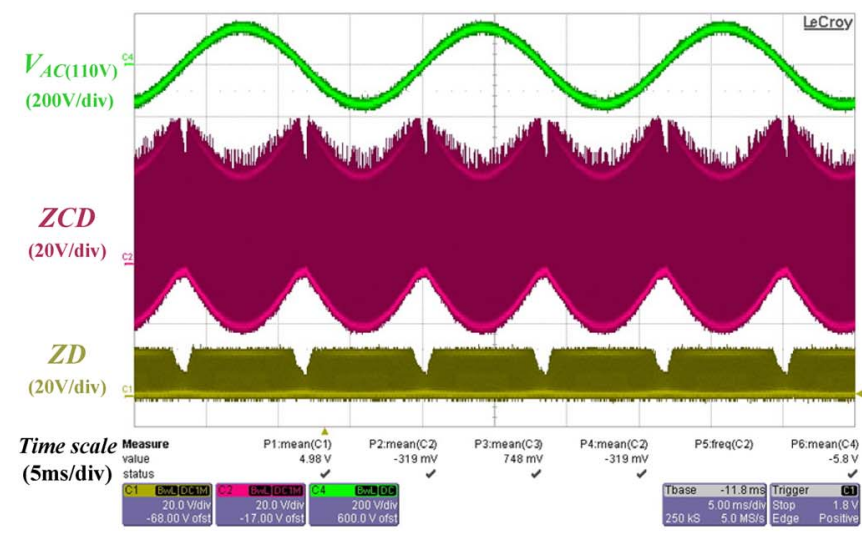

(a)

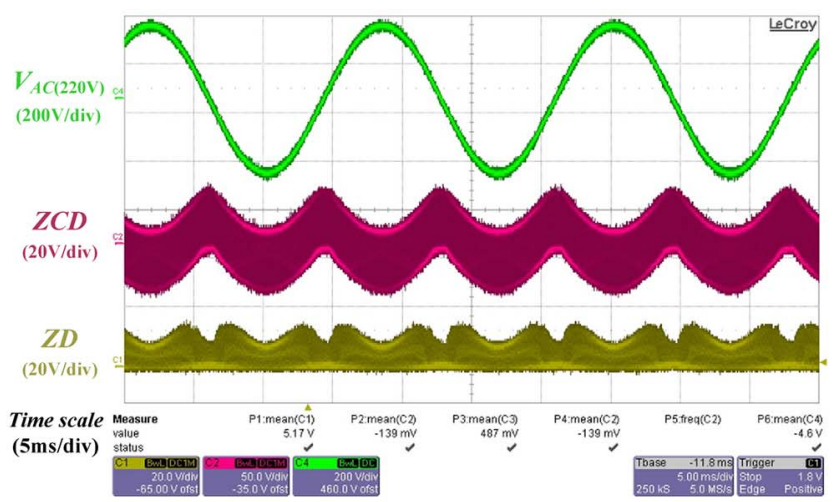

(b)

Fig. 18. Measured waveforms of the ZCD circuit at the input line RMS voltages of (a) $110 \mathrm{~V}$ and (b) $220 \mathrm{~V}$.

Fortunately, $I_{\mathrm{ZD}}$ includes the line voltage information. That is, a high line voltage produces larger $I_{\mathrm{ZD}}$. Contrarily, a low line voltage produces smaller $I_{\mathrm{ZD}}$. The THDI technique mirrors $I_{\mathrm{ZD}}$ to modulate the on-time value of the power nMOSFET under four different input line RMS voltages. As the LVR detects the level of the input line RMS voltage, only one switch among $M_{3}-M_{16}$ will be turned on, and the selected current $I_{\text {opt }}$ will charge the $V_{\text {saw }}$ to adjust the ontime value. Therefore, the slope of $V_{\text {saw }}$ is proportional to the line voltage, owing to the dependence of $I_{\mathrm{opt}}$ on the line voltage.

As shown in Fig. 12(a), serious crossover distortion with large flat portion happens in conventional PFC with constant on-time control. Since the power delivered to output in one ac line cycle is fixed with constant load condition, the output power can be manipulated within an ac line cycle. In other words, if the on-time at high $V_{\text {in }}$ decreases, the on-time near zero-crossings must be increased to provide enough power. Therefore, the current near zero-crossings can break through $I_{\text {limit }}$ and shorten the flat portion of the line current, as shown in Fig. 12(b).

The adjusted $V_{\text {saw }}$ is controlled by two components. The first component is $I_{\text {saw }}$ in Fig. 7, which is used to generate the $V_{\text {saw }}$ with the charging slope of $S_{\text {saw }}$ in conventional PFC originally. $I_{\mathrm{opt}}$, which alters the charging slope by $S_{\mathrm{opt}}$ for on-time modulation, forms the second component. Since $V_{\text {saw }}$ is limited in the range of $V_{\mathrm{saw}, \mathrm{dc}}$ and $V_{\mathrm{EAO}}$, as shown in 


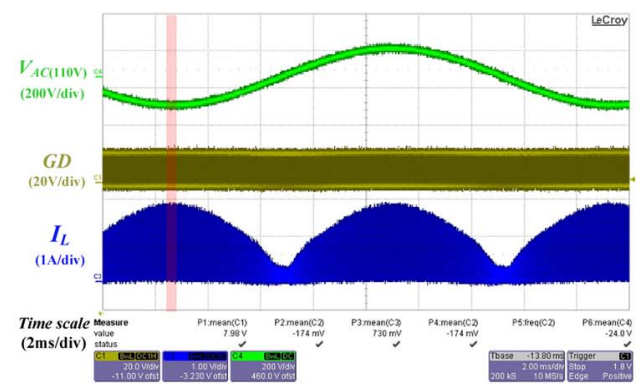

(a)

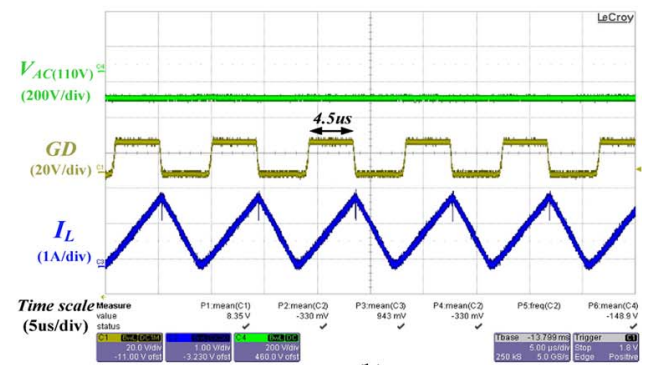

(b)

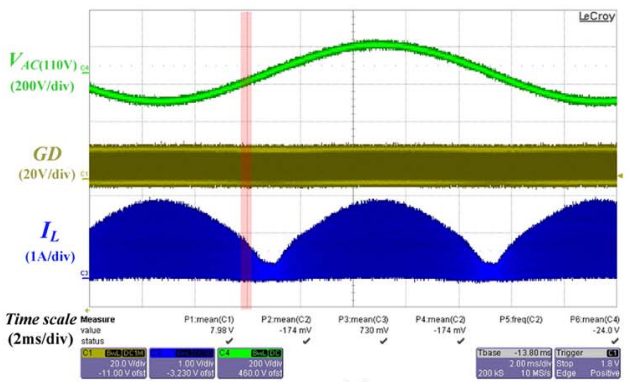

(c)

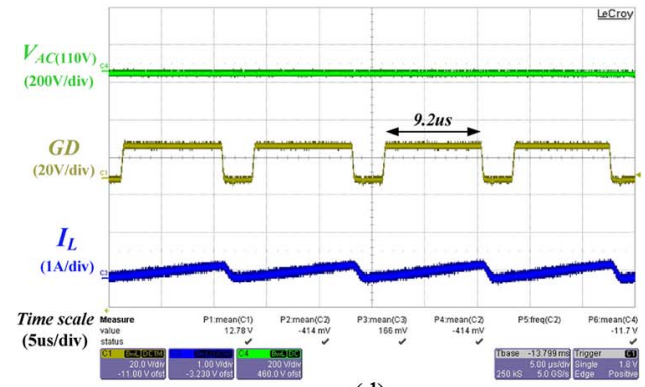

(d)

Fig. 19. (a) Measured waveforms of the gate signal and the inductor current at the high level of the line voltage. (b) Zoom in on the red region of (a). (c) Measured waveforms of the gate signal and the inductor current at the low level of the line voltage. (d) Zoom in on the red region of (c).

Fig. 12(b), the on-time value of the power nMOSFET after modulation is derived in

$$
\begin{gathered}
t_{\text {on }, \text { proposed }}=\frac{V_{\mathrm{EAO}}-V_{\mathrm{saw}, \mathrm{dc}}}{S_{\mathrm{saw}}+S_{\mathrm{opt}}}=\left(V_{\mathrm{EAO}}-V_{\mathrm{saw}, \mathrm{dc}}\right) \\
\times\left(S_{\mathrm{saw}}+\frac{\left(V_{\mathrm{ZD}, \text { clamp }}+\frac{V_{\mathrm{IN}} \cdot N_{\mathrm{aux}}}{N_{b}}\right) \times M_{i}}{R_{\mathrm{ZD}} \times C_{\mathrm{saw}}}\right)^{-1}
\end{gathered}
$$

where $V_{\mathrm{EAO}}$ is the output voltage of the error amplifier. $V_{\text {saw,dc }}$ is the designed lower bound of the sawtooth signal. $S_{\text {saw }}$ and $S_{\text {opt }}$ are the charging slopes of $I_{\text {saw }}$ and $I_{\text {opt }}$, respectively, to charge $C_{\text {saw }} . M_{i}$ is the optimal mirror ratio for THD minimization.

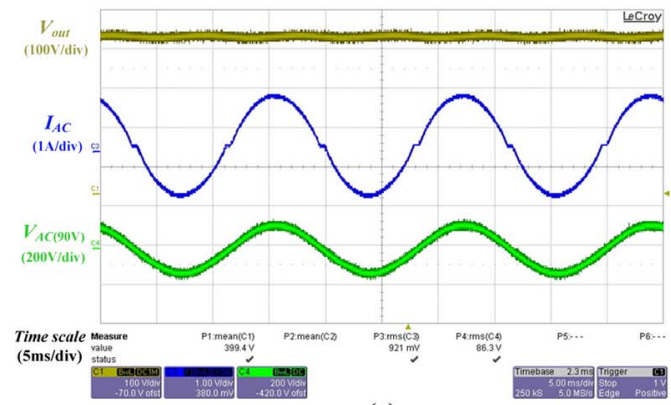

(a)

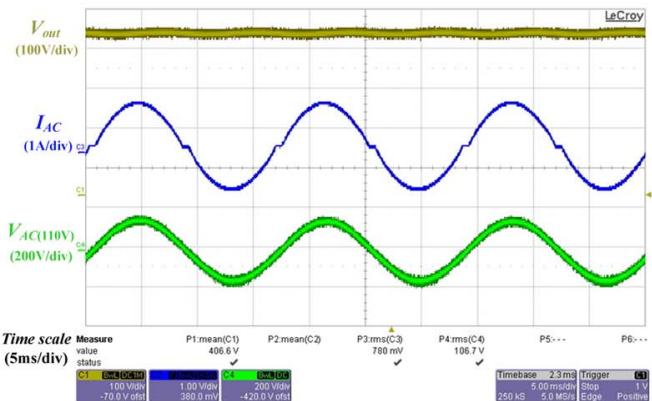

(b)

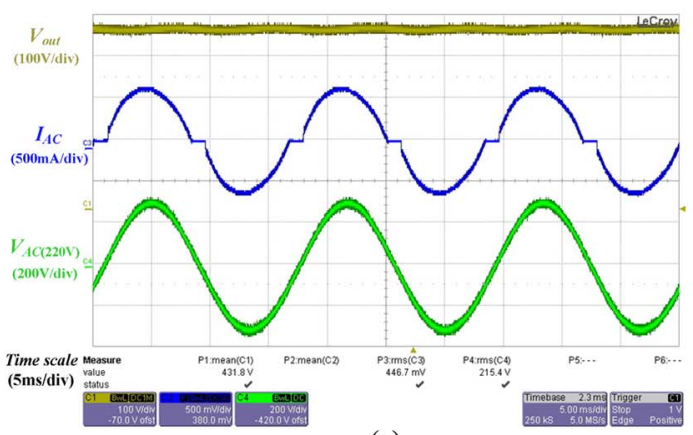

(c)

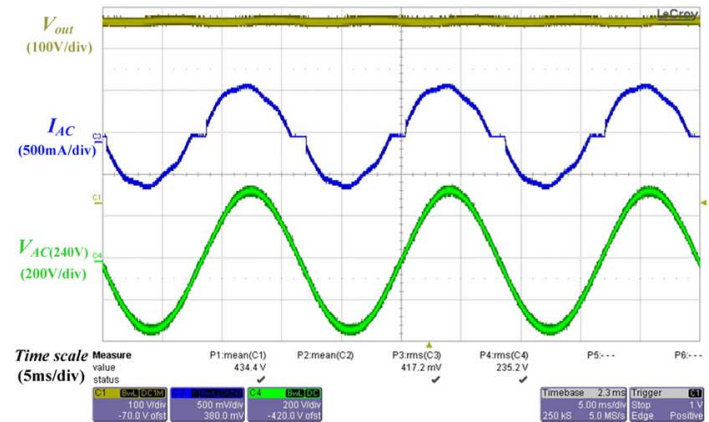

(d)

Fig. 20. Measured waveforms of the output voltage and the line current at the input line RMS voltages of (a) $90 \mathrm{~V}$, (b) $110 \mathrm{~V}$, (c) $220 \mathrm{~V}$, and (d) $240 \mathrm{~V}$.

It is worth to be mentioned that there exists a distinct optimal mirror ratio, i.e., $M_{i}$, at different line RMS voltages. That is, the ratio of $M_{5}, M_{6}, M_{7}$, and $M_{8}$ to $M_{1}$ are $M_{90}, M_{110}, M_{220}$, and $M_{264}$, respectively. To obtain the optimal mirror ratio, the relationship between the THD and the mirror ratio at different line RMS voltages is illustrated in Fig. 13. Therefore, the $M_{90}$, $M_{110}, M_{220}$, and $M_{264}$ ratio is designed for the optimal on-time modulation value to obtain the minimum THD at different line voltages.

The output ripple with twice the ac line frequency is fed into the feedback loop, as shown in Fig. 14. The frequency of averaged diode current $I_{\text {diode,ave }}$, which is twice the ac line 


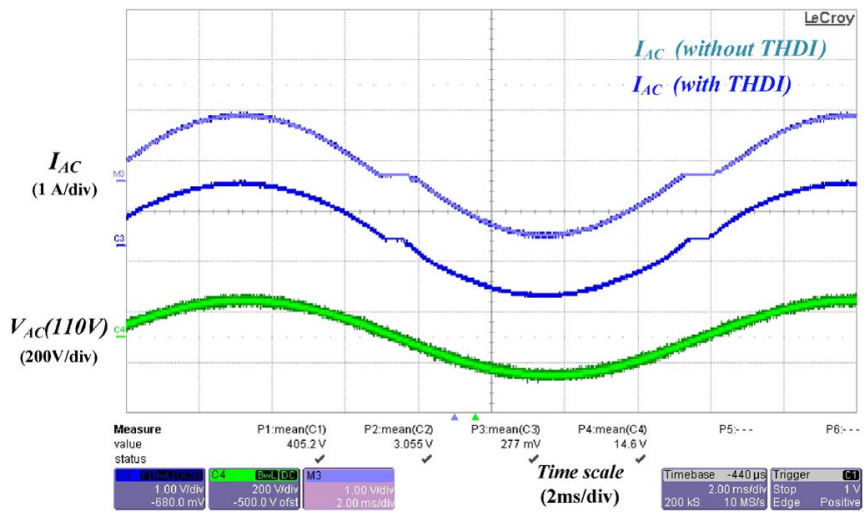

Fig. 21. Measured line voltage and line current waveforms at $V_{\mathrm{AC}}$ of $110 \mathrm{~V}$ with and without the proposed THDI.

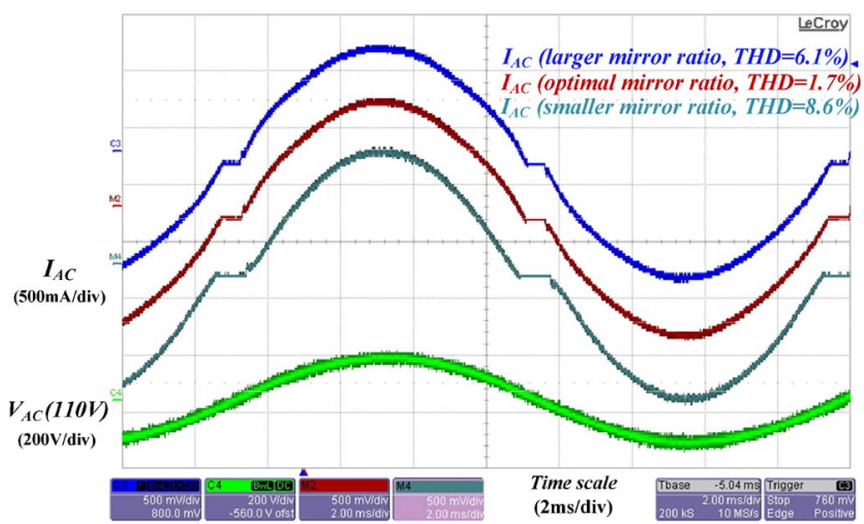

Fig. 22. Measured line voltage and line current waveforms with different mirror ratios.

frequency, is derived in (11), shown at the bottom of the page, where $I_{\text {diode }}$ is the diode current of the power stage, and $I_{\text {out }}$ is a constant loading current. When $I_{\text {diode, ave }}$ is larger than $I_{\text {out }}$, $C_{\text {out }}$ is charged. When $I_{\text {diode, ave }}$ is smaller than $I_{\text {out }}, C_{\text {out }}$ is discharged. Thus, the voltage ripple frequency of $V_{\text {out }}$ is also twice the ac line frequency, and the ripple at $V_{\text {out }}$ is derived as (12). As long as the ripple, which is fed into the feedback loop, can be reduced, the line frequency reflected distortion can be improved as

$$
\begin{aligned}
\Delta V_{\text {out }} & =\frac{\int_{\frac{3}{8 f_{\text {line }}}}^{\frac{3 f_{\text {line }}}{2}}\left(I_{\text {diode, ave }}-I_{\text {out }}\right) d t}{C_{\text {out }}} \\
& =\frac{I_{\text {out }}}{2 \pi \cdot f_{\text {line }} \cdot C_{\text {out }}} .
\end{aligned}
$$

The ripple compensator is used to further alleviate the line frequency reflected distortion. The idea of the ripple compensator is to inject a sinusoidal-like and out-of-phase current $I_{s p}$

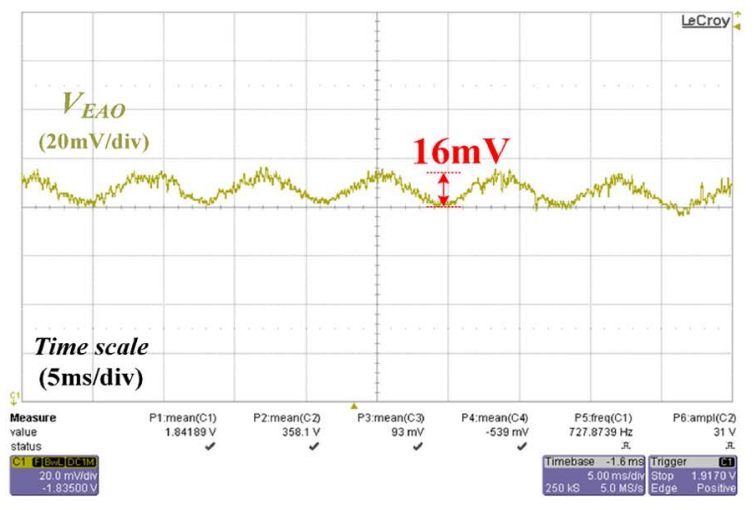

(a)

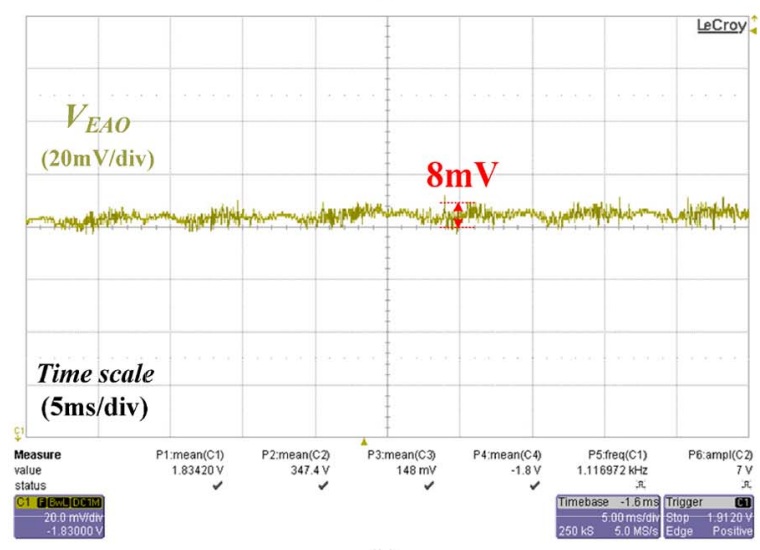

(b)

Fig. 23. Measured error amplifier output ripple (a) without the ripple compensator in the THDI and (b) with the ripple compensator in the THDI.

with respect to the current ripple flowing through the feedback resistor $R_{\mathrm{fb} 1}$, i.e., $\Delta I_{\mathrm{Rfb} 1}$. As a result, the output ripple of the error amplifier, i.e., $V_{\mathrm{EAO}}$, can be reduced such that the ontime variation is decreased to improve the THD, as shown in Fig. 15.

Since a sinusoidal-like current is needed, the voltage $V_{S}$ from the LVR has to be processed by the envelope detector, which is composed of COM2, $M_{17}, R_{e}$, and $C_{e}$. By $C_{\mathrm{rc}}$, the out-ofphase current $I_{s p}$ is generated and injected into $V_{\mathrm{fb}}$. Since $V_{\mathrm{fb}}$ decides the regulated voltage at the output, any dc value of $I_{s p}$ deteriorates the regulation performance. Fortunately, $C_{\mathrm{rc}}$ blocks the dc components of $I_{s p}$. Therefore, the output voltage is not affected by the ripple compensator.

To conquer the line frequency reflected distortion, the design of $C_{\mathrm{rc}}$ is crucial. Since the goal of the ripple compensator is to eliminate the ripple of $V_{\mathrm{FB}}, V_{\mathrm{FB}}$ can be viewed as ac ground.

$$
\begin{aligned}
I_{\text {diode }, \text { ave }} & =\frac{\left[\sqrt{2} \cdot V_{\mathrm{AC}, \mathrm{rms}} \cdot \sin \left(2 \pi f_{\text {line }} t\right)\right] \times\left[\sqrt{2} \cdot I_{\mathrm{AC}, \mathrm{rms}} \cdot \sin \left(2 \pi f_{\text {line }} t\right)\right] \times \eta}{V_{\text {out }}} \\
& =\frac{V_{\mathrm{AC}, \mathrm{rms}} \times I_{\mathrm{AC}, \mathrm{rms}}}{V_{\text {out }}} \times\left(1-\cos \left(4 \pi f_{\text {line }} t\right)\right) \times \eta \\
& =I_{\text {out }} \cdot\left(1-\cos \left(4 \pi f_{\text {line }} t\right)\right)
\end{aligned}
$$




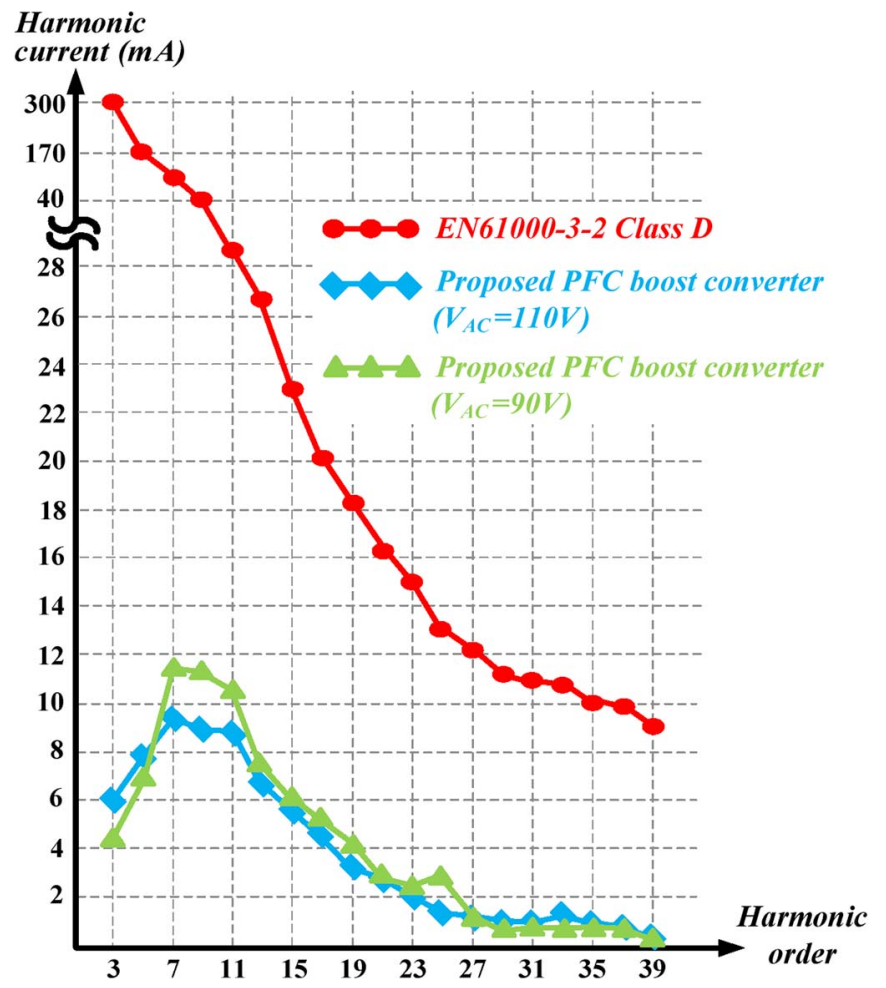

Fig. 24. Measured harmonic current and EN61000-3-2 class D regulation at the output power of $90 \mathrm{~W}$.

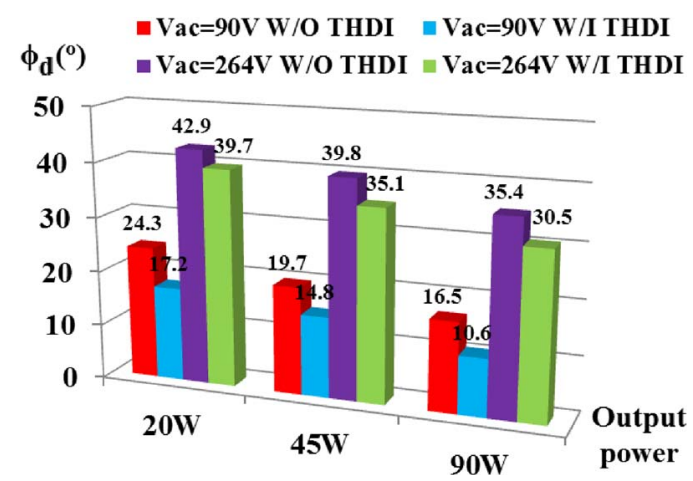

Fig. 25. Measured crossover distortion angle at different output power and line voltage conditions with and without the proposed THDI.

Thus, the current that flows from $V_{\text {out }}$ to $V_{\mathrm{FB}}, \Delta I_{\mathrm{Rfb} 1}$, and compensation current $I_{s p}$ are cancelled at $V_{\mathrm{FB}}$, as shown in

$$
\Delta I_{\mathrm{Rfb} 1}+I_{s p}=0 .
$$

Since $\Delta I_{\mathrm{Rfb} 1}$ and $I_{s p}$ are out of phase, (14) can be derived from (13) as

$$
\frac{\Delta V_{\text {out }}}{R_{\mathrm{fb} 1}}-\frac{\Delta V_{s p}}{1 / s C_{\mathrm{rc}, \mathrm{opt}}}=0
$$

where $\Delta V_{\text {out }}$ is the ripple of the output voltage. $\Delta V_{s p}$ is the peak-to-valley amplitude of $V_{s p}$. Consequently, the optimal value of $C_{\mathrm{rc}}$ can be derived in

$$
C_{\mathrm{rc}, \mathrm{opt}}=\frac{\Delta V_{\mathrm{out}}}{2 \pi f_{\text {line }} \cdot \Delta V_{s p} \cdot R_{\mathrm{fb} 1}}
$$

where $f_{\text {line }}$ is the line frequency.

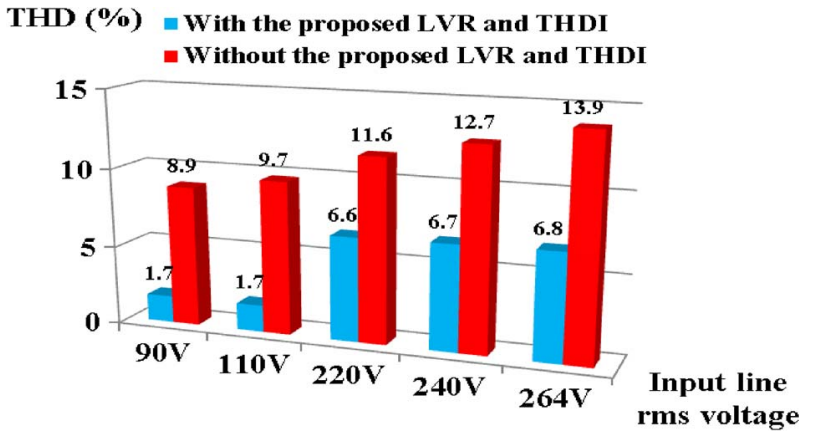

Fig. 26. Comparison diagram of the THD at the output power of $90 \mathrm{~W}$ with different input line RMS voltages.

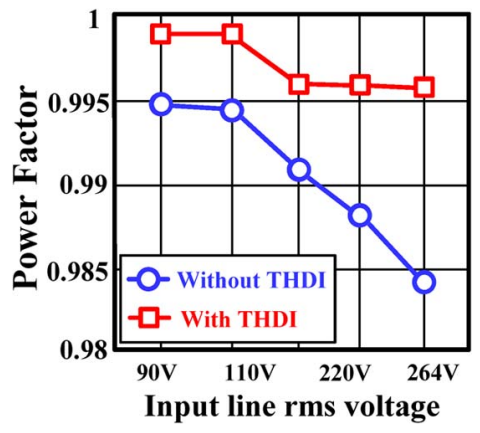

Fig. 27. Comparison diagram of the PF at the output power of $90 \mathrm{~W}$ with different input line RMS voltages.

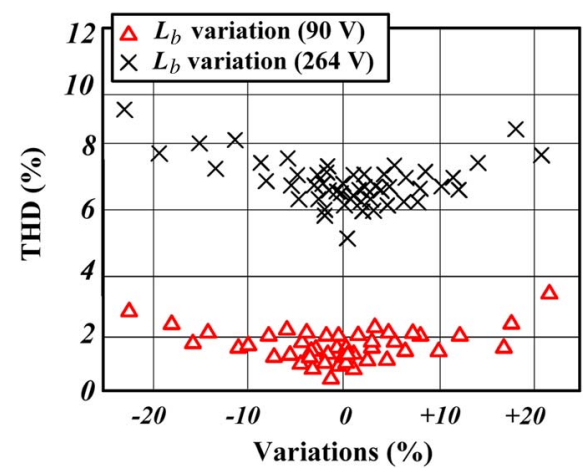

Fig. 28. Monte Carlo analysis of THD with inductance $L_{b}$ variation at $V_{\mathrm{rms}}=90 \mathrm{~V}$ and $V_{\mathrm{rms}}=264 \mathrm{~V}$.

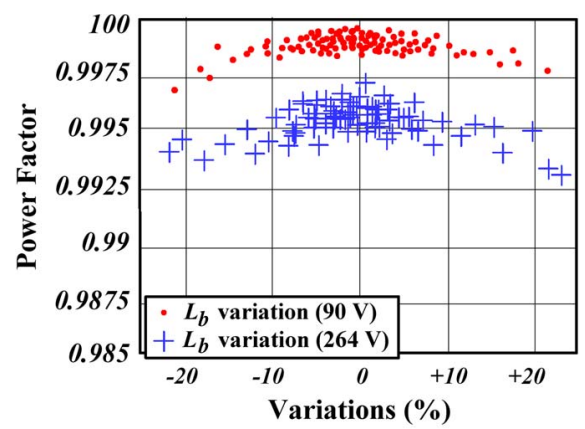

Fig. 29. Monte Carlo analysis of PF with inductance $L_{b}$ variation at $V_{\mathrm{rms}}=$ $90 \mathrm{~V}$ and $V_{\mathrm{rms}}=264 \mathrm{~V}$.

\section{Simulation And Experimental Results}

The proposed PFC controller with the LVR and the THDI was fabricated in a TSMC $0.5-\mu \mathrm{m} 800-\mathrm{V}$ ultrahigh-voltage (UHV) process. The chip micrograph is shown Fig. 16, and the 
TABLE II

Comparisons Between Proposed Method and Prior Arts

\begin{tabular}{|c|c|c|c|c|c|}
\hline & This work & [7] & [11] & {$[12]$} & {$[13]$} \\
\hline Input line voltage & $90 \sim 264 \mathrm{~V}$ & $90 \sim 264 \mathrm{~V}$ & $85 \sim 265 \mathrm{~V}$ & $115 \mathrm{~V}$ & $85 \sim 265 \mathrm{~V}$ \\
\hline Output voltage & $400 \mathrm{~V}$ & $400 \mathrm{~V}$ & $392.5 \mathrm{~V}$ & $\mathrm{~N} / \mathrm{A}$ & $395 \mathrm{~V}$ \\
\hline Output power & $90 \mathrm{~W}$ & $90 \mathrm{~W}$ & $300 \mathrm{~W}$ & $50 \mathrm{~W}$ & $80 \mathrm{~W}$ \\
\hline Circuit integrated & Fully integrated & Fully integrated & System level & System level & Fully integrated \\
\hline Control methodology & Analog & Analog & Digital & Digital & Analog \\
\hline Efficiency (maximum) & $94.8 \%$ & $95 \%$ & $99.17 \%$ & $94.7 \%$ & $97 \%$ \\
\hline THD (minimum) & $1.7 \%$ & $8 \%$ & $3.59 \%$ & $5 \%$ & $3.6 \%$ \\
\hline Power factor & 0.998 & 0.99 & 0.985 & 0.996 & 0.998 \\
\hline
\end{tabular}

specifications are listed in Table I. Fig. 17 shows the current sensing signal $V_{\mathrm{CS}}$ and the reconstructed line voltage $V_{S}$ with different RMS line voltages. It is proved that the sinusoidalwave tendency of the line voltage can be reconstructed by LVR without any extra pins. The waveforms of the ZCD circuit are shown in Fig. 18. Although the voltage of node ZCD varies in a wide range, the highest voltage of the $\mathrm{ZD}$ pin, which is connected to the integrated circuit, is clamped to about $20 \mathrm{~V}$, determined by the breakdown voltage of the ZD in the ZCD circuit. In addition, the lowest voltage of the $\mathrm{ZD}$ pin is clamped to a quite low voltage higher than $0 \mathrm{~V}$ by the negative feedback in the ZCD circuit.

Fig. 19 shows the measured on-time, which is modulated by the THDI at the high and low levels of the line voltage. When the line voltage is at a high level, the on-time is about $4.5 \mu \mathrm{s}$. When the line voltage is at a low level near zero-crossings, the on-time is longer about $9.2 \mu \mathrm{s}$. Therefore, the crossover distortion can be effectively improved by on-time modulation according to the line voltage.

At the output power of $90 \mathrm{~W}$, the measured waveforms of the output voltage and the line current at different line RMS voltages are shown in Fig. 20. The output voltage is regulated at $400 \mathrm{~V}$. To provide power to equipment for general purpose, the $400 \mathrm{~V}$ is applied to the next dc-dc converter stage such as quasiresonant and primary side regulator to step down the dc voltage. The line current is a sinusoidal wave, which is in phase with the line voltage by the proposed LVR and THDI techniques. Thus, the $\mathrm{PF}$ at different line voltages is higher than 0.99 .

Fig. 21 shows the measured line voltage and line current waveforms with and without the proposed THDI. Fig. 22 shows the measured line voltage and current waveforms with different mirror ratios in the THDI at the output power of $90 \mathrm{~W}$. Compared with the optimal mirror ratio, a larger or a smaller mirror ratio results in poor THD performance. In Fig. 23, the proposed ripple compensator effectively suppresses the output ripple of the error amplifier by $50 \%$, which is decreased from 16 to $8 \mathrm{mV}$. In other words, the capacitance of $C_{C}$ can be reduced by $50 \%$ by the feedforward path formed in the ripple compensator. Converting to the decrement of the chip area, the capacitor $C_{C}$ occupies 0.98 and $0.49 \mathrm{~mm}^{2}$ without and with the ripple compensator, respectively. However, the ripple compensator occupies only $0.06 \mathrm{~mm}^{2}$. Consequently, the chip area of $0.43 \mathrm{~mm}^{2}$ can be saved to lower the cost of the PFC.

The measured harmonic currents with the output power of $90 \mathrm{~W}$ at the input line RMS voltages of 90 and $110 \mathrm{~V}$ are shown in Fig. 24. It can be seen that the EN61000-3-2 class $\mathrm{D}$ regulation is met with enough design margin. Fig. 25 shows the measured crossover distortion angle at different output power and line voltage conditions. Without THDI, a crossover distortion angle of $42.9^{\circ}$ happens at the output power of $20 \mathrm{~W}$ and $V_{\mathrm{ac}}$ of $264 \mathrm{~V}$. The crossover distortion angles at all conditions are suppressed by modulating the on-time in THDI. Fig. 26 shows that the measured THD can be reduced to $1.7 \%$ at the line RMS voltage of $90-110 \mathrm{~V}$ and kept within $7 \%$ at the line RMS voltage of 90-264 V with the help of the proposed LVR and THDI. Fig. 27 shows that the measured PF is higher than 0.995 at different line RMS voltages with the output power of $90 \mathrm{~W}$. Considering the devices mismatch of the proposed PFC controller, the THD and PF performance is mainly affected by the inductance variation. In Figs. 28 and 29, the Monte Carlo analyses of THD and PF with inductance $L_{b}$ variation at $V_{\mathrm{rms}}=90 \mathrm{~V}$ and $V_{\mathrm{rms}}=264 \mathrm{~V}$ are shown, respectively. Even though the THD and PF performance is slightly affected by the inductance variation, Monte Carlo analyses show that the tolerance of the inductance variation can be as high as $20 \%$ with the proposed THDI. The comparisons between the proposed method and prior arts are listed in Table II.

\section{Conclusion}

The proposed LVR can detect the input line RMS voltage to generate the digital equivalent code to the THDI for optimizing the THD by tuning the on-time value at different line voltages. In addition, the LVR and the THDI provide a feedforward path to reduce the ripple of the feedback voltage for decreasing the THD. Experimental results show that the THD can be reduced to $1.7 \%$ at the line voltage of $90-110 \mathrm{~V}$ and that the PF is higher than 0.995 at different line voltages. Furthermore, the THD can be kept within $7 \%$ at universal line voltages. The test circuit was fabricated in a TSMC 800-V UHV process.

\section{REFERENCES}

[1] L. Hang, M. Zhang, L. M. Tolbert, and Z. Lu, "Digitized feedforward compensation method for high-power-density three-phase Vienna PFC converter," IEEE Trans. Ind. Electron., vol. 60, no. 4, pp. 1512-1519, Apr. 2013.

[2] J. W. Kim, S. M. Choi, and K. T. Kim, "Variable on-time control of the critical conduction mode boost power factor correction converter to improve zero-crossing distortion," in Proc. IEEE Power Electron. Drive Syst. Conf., Nov. 2005, pp. 1542-1546.

[3] S.-H. Tang, D. Chen, C.-S. Huang, C.-Y. Liu, and H. Liu, "A new on-time adjustment scheme for the reduction of input current distortion of criticalmode power factor correction boost converters," in Proc. IEEE Int. Power Electron. Conf., Jun. 2010, pp. 1717-1724

[4] K. Yao, X. Ruan, X. Mao, and Z. Ye, "Variable-duty-cycle control to achieve high input power factor for DCM boost PFC converter," IEEE Trans. Ind. Electron, vol. 58, no. 5, pp. 1856-1865, May 2011. 
[5] H. S. Athab, "Single-phase single-switch boost PFC regulator with low total harmonic distortion and feedforward input voltage," in Proc. IEEE Power Energy Conf., Dec. 2008, pp. 1118-1123.

[6] "L6561 datasheet: Transition-mode PFC controller," Geneva, Switzerland, Rev. 8, Nov. 2004.

[7] J. C. Tsai, C. L. Chen, Y. T. Chen, C. L. Ni, C. Y. Chen, K. H. Chen, C. J. Chen, and H. L. Pan, "Perturbation on-time (POT) control and inhibit time control (ITC) in suppression of THD of power factor correction (PFC) design," in Proc. Custom Integr. Circuits Conf., Sep. 2011, pp. 1-4.

[8] K. De Gusseme, D. M. Van de Sype, A. P. M. Van Den Bossche, and J. A. Melkebeek, "Input-current distortion of CCM boost PFC converters operated in DCM," IEEE Trans. Ind. Electron., vol. 54, no. 2, pp. 858865, Apr. 2007

[9] "SG6901A datasheet: CCM PFC/flyback PWM combination controller," San Jose, CA, USA, Rev. 1.0.2, Feb. 2009.

[10] Y. H. Lee, S. J. Wang, and K. H. Chen, "Quadratic differential and integration technique in $\mathrm{V}^{2}$ control buck converter with small ESR capacitor," IEEE Trans. Power Electron., vol. 25, no. 4, pp. 829-838, Apr. 2010.

[11] S. F. Lim and A. M. Khambadkone, "A simple digital DCM control scheme for boost PFC operating in both CCM and DCM," IEEE Trans. Ind. Appl., vol. 47, no. 4, pp. 1802-1812, Jul./Aug. 2011.

[12] F. Z. Chen and D. Maksimovic, "Digital control for improved efficiency and reduced harmonic distortion over wide load range in boost PFC rectifiers," IEEE Trans. Power Electron., vol. 25, no. 10, pp. 2683-2692, Oct. 2010.

[13] "L6562 datasheet: Transition-mode PFC controller," Geneva, Switzerland, Rev. 8, Nov. 2005.

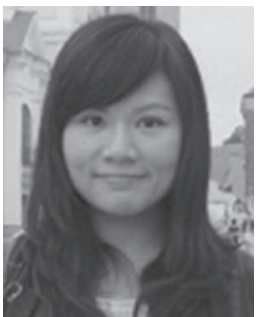

Yi-Ping Su (S'12) was born in Taipei, Taiwan. She received the B.S. degree from National Sun Yat-sen University, Kaohsiung, Taiwan, in 2009. She is currently working toward the Ph.D. degree in the Institute of Electrical Engineering, National Chiao Tung University, Hsinchu, Taiwan.

She is also currently a Member with the MixedSignal and Power Management IC Laboratory, Institute of Electrical Engineering, National Chiao Tung University. Her current research interests include power management and analog IC designs.

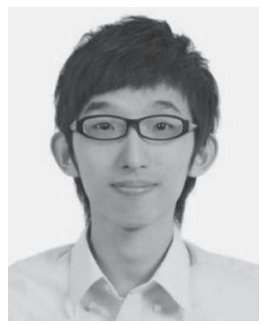

Chia-Lung Ni was born in Keelung, Taiwan. He received the B.S. degree from National Chung Hsing University, Taichung, Taiwan, in 2010 . He is currently working toward the M.S. degree in the Institute of Electrical and Control Engineering, National Chiao Tung University, Hsinchu, Taiwan.

$\mathrm{He}$ is also currently a Faculty Member with the Mixed-Signal and Power Management IC Laboratory, Institute of Electrical Control Engineering, National Chiao Tung University. His research interests include power factor correction design, power management IC design, and analog ICs.

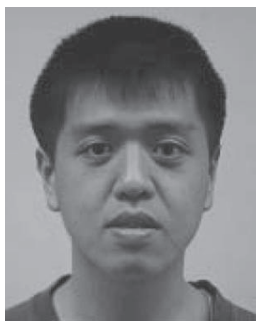

Chun-Yen Chen was born in Keelung, Taiwan. $\mathrm{He}$ received the B.S. degree from National Taipei University of Technology, Taipei, Taiwan, in 2010. $\mathrm{He}$ is currently working toward the M.S. degree in the Institute of Electrical and Control Engineering, National Chiao Tung University, Hsinchu, Taiwan.

$\mathrm{He}$ is also currently a Faculty Member with the Mixed-Signal and Power Management IC Laboratory, Institute of Electrical Control Engineering, National Chiao Tung University. His research interests include power factor correction IC design, the power management IC design, and analog ICs.

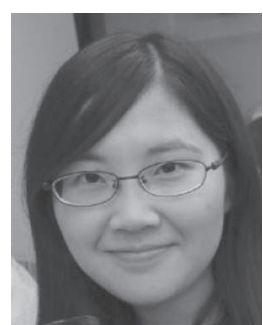

Yi-Ting Chen was born in Taipei, Taiwan. She received the B.S. degree from Chang Gung University, Taoyuan, Taiwan, in 2007. She is currently working toward the M.S. degree in the Institute of Electrical and Control Engineering, National Chiao Tung University, Hsinchu, Taiwan.

She is also currently a Faculty Member with the Mixed-Signal and Power Management IC Laboratory, Institute of Electrical Control Engineering, National Chiao Tung University. Her research interests include power factor correction IC design, power management IC design, and analog ICs.

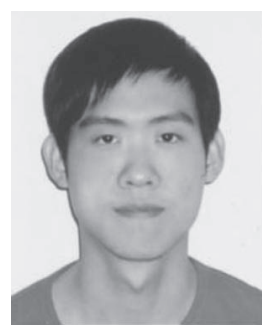

Jen-Chieh Tsai received the B.S. degree from National Yunlin University of Science and Technology, Yunlin, Taiwan, in 2003 and the M.S. degree from Tamkang University, Taipei, Taiwan, in 2005. He is currently working toward the Ph.D. degree in the Institute of Electrical Control Engineering, National Chiao Tung Univerity, Hsinchu, Taiwan.

$\mathrm{He}$ is also currently a Faculty Member with the Mixed-Signal and Power Management IC Laboratory, Institute of Electrical Control Engineering, National Chiao Tung University. His research area includes many projects on high-resolution analog-to-digital converter, low-power digital-to-analog converter, and power management ICs at the LowPower Mixed Signal Laboratory. His research interests include power management circuit designs, power factor correction ICs, and analog IC designs.

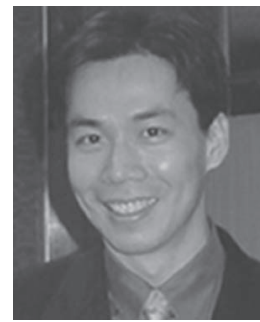

Ke-Horng Chen (M'04-SM'09) received the B.S., M.S., and Ph.D. degrees in electrical engineering from National Taiwan University, Taipei, Taiwan, in 1994, 1996, and 2003, respectively.

From 1996 to 1998 , he was a part-time IC Designer with Philips, Taipei. From 1998 to 2000, he was an Application Engineer with Avanti Ltd. Taiwan. From 2000 to 2003, he was a Project Manager with ACARD, Ltd., where he was engaged in designing power management ICs. He is currently the Director of the Institute of Electrical Control Engineering, National Chiao Tung University, Hsinchu, Taiwan, and a Professor with the Department of Electrical Engineering, National Chiao Tung University, where he organized the Mixed-Signal and Power Management IC Laboratory. He has authored or coauthored more than 100 papers published in journals and conferences, and is a holder of several patents.

Dr. Chen has served as an Associate Editor of the IEEE TRANSACTIONS on Power EleCtronics and IEEE TRANSACTIONS ON CirCUITS AND SYSTEMS-PART II: EXPRESS BRIEFS. He also has been on the Editorial Board of Analog Integrated Circuits and Signal Processing since 2013. 